\title{
$\mathbb{P e} /$ int und die $\mathfrak{R u n t}$.
}

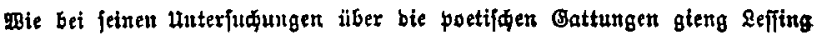

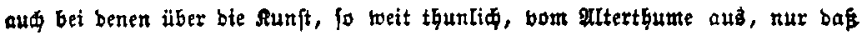
ighn bier bie alten rheoretiler weniger unterfiuttet, als 2rriftoteles in ber Poetil.

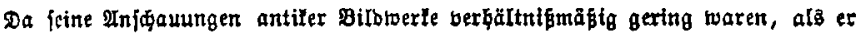
fh ben unterjutungen über bie bilbenben silnite zutwanbte, fo mugte er bon

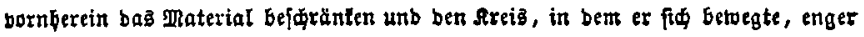

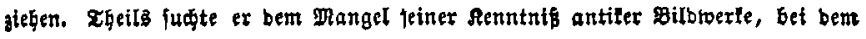

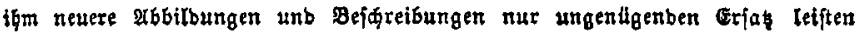

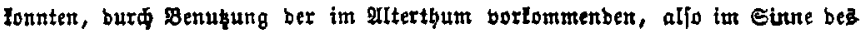

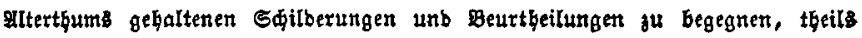

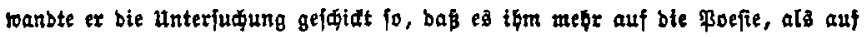
bie plaftil antommen muste. Inb in ber \&bat fub feine unterfudurgen, beren

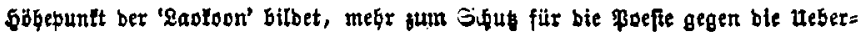

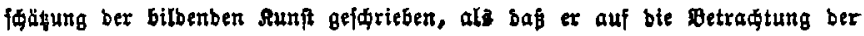

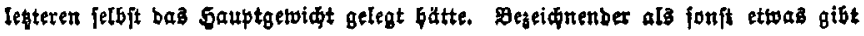
ber Sak, ben ex bet ber Interfieibung bes alterthumbiträmers von bem IIter= thumąurbigen bittrirft, feinen Stanbpunlt gu erlentnen, ber Sał, bas ber Arämer

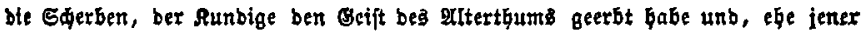

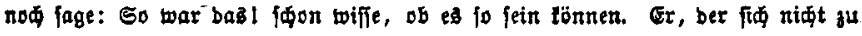

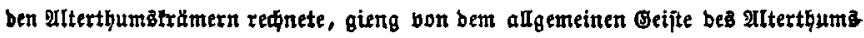

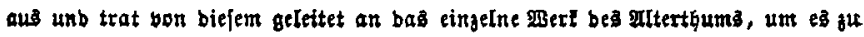
extennen unb a beurtbeilen.

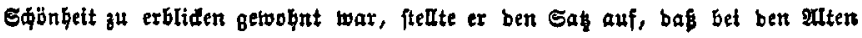

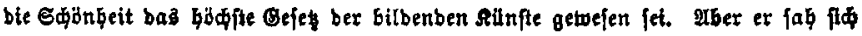

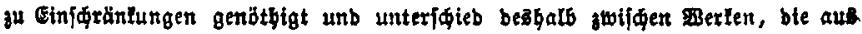
bäliger freibeit ber Runftler berborgegangen, unb gwifden folden, bie burd

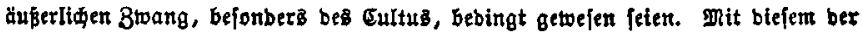

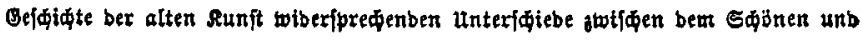
bem Bebeutenden tonnte ex feine Begner leiđt wiberlegen unb bas, was than ent-

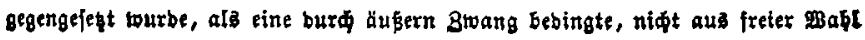


bes Riunfters Gerborgegangene Sфupfung zur Seite f中ieber, um bann bon ben Aunftwerten, bie biefen Tamen in feinem Sinte berbienten, Regeln berjuleiten, bie nidit aus ben nothwenbigen Befeşen ber \$laftil, ber Begrenzung ber Эbee in törperliqen formen, abgeleitet werben tontten. Die Srunblage feiner ibeorie ber bubenber sünfte berubte aljo auf einer fictiou unb bie ₹heorie felbft lonute

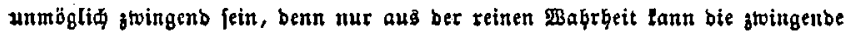
ueberzeugung berbortreten.

Es lam \&effing aber weniger auf bie riditige Crlenttntis ber plaftifien Sunft, a[B auf bie Befettigung ber bilettantiffen $\mathfrak{U}$ fufaffung berfelben unb auf bie Sont

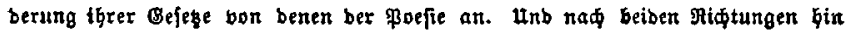
war ex, tro jenes orunbirrtbums, febr vom đrfolg begüuftigt.

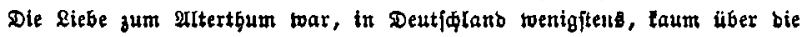
Siebbaberei binaug̈glommen. Dtan fammelte, too reiqere Mittel ou Gebote ftauben,

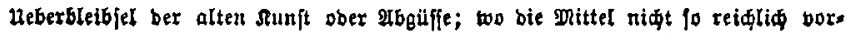

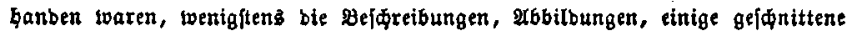

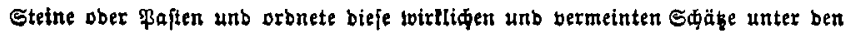

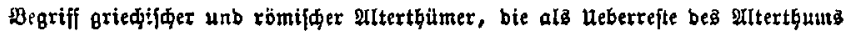

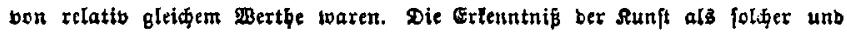

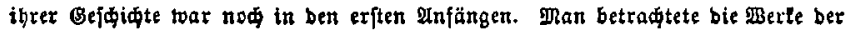

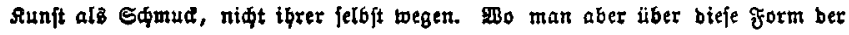

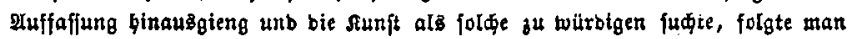

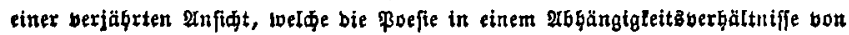

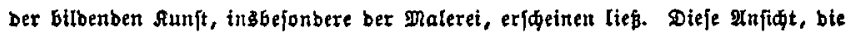

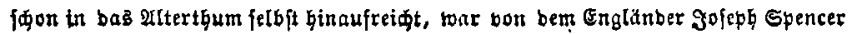

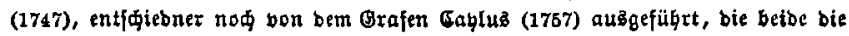

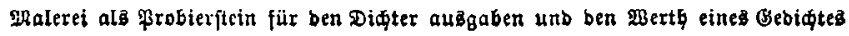
babou abjängig madten, wie tweit es bem Maler Stoff biete. Diefelbe Mnj

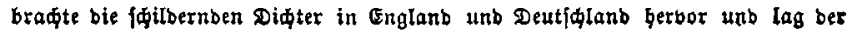

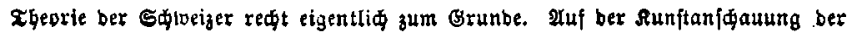
Edweiger, \$obmerßె unb Breitingers̄, fupte aber wieberum \$intelmann in feinen.

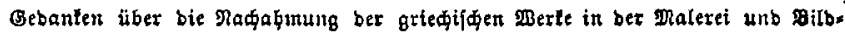

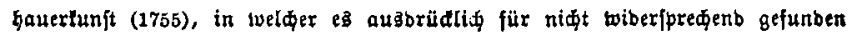
Jourbe, bas bie Dialerei ebenjo toeite Brengen als bie Didtlunft haben tönte, unb

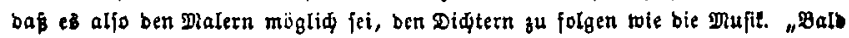
groingt man," fagt Reffing, "bie Foefie in bie engen Sdgranten ber Maleret, balb läßt man bie Malerei bic ganze weite Sphärc ber \$oefie füllen." Diafe Bletw. ftellung ber Mlalerei unb qoefie reigte Deffing fur Deriqtigung ibrer Brenger. In: bem er rein aprioriftifd aus ben beiber sünften aน Bebote ftebenben Dritteln, ble

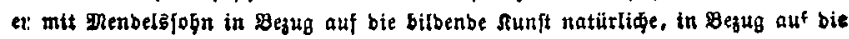


Foefie millürlique Zeiqen neint, bie Beftimmung ber Bremgen getoan, wollte et bie Auffinburg berfelben bem Stubium Gomers ju verbanten haben, aus bem er

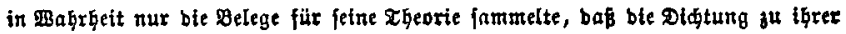

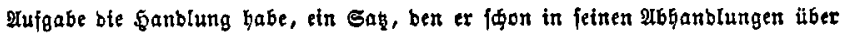
bie Gabel aufgeftellt unb burdgeführt Gatte. Das gefentlide biefer Theorie ift in Der Cisteitung ou ben Gabeln felbft zufammengefast worben. Jm Laoloon gieng

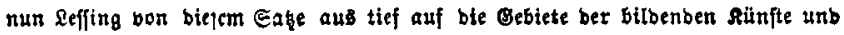
ber Diфtungşgattungen ein. Die erfteren, bie ex unter bem Borte Dalerei gu= jammengreift, 佸ränlte er auf einen etngigen פoment einer f̧anblung ein, ber

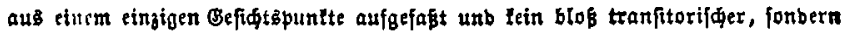

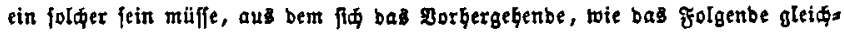

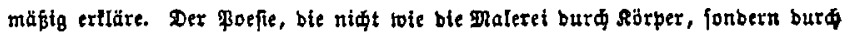
Iaute rebe, wies er bie fortffrettenbe Radbilbung einer Sanblung ju, beren Bes wegung jeber einjelne Dloment berfelben untergeorbnet fetn milfie. Dabei entoidelt

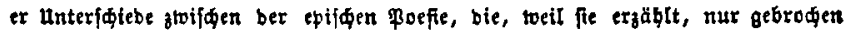

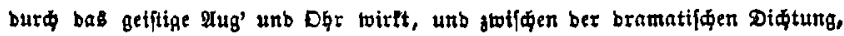

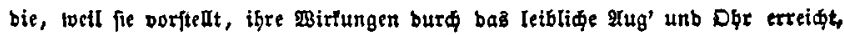

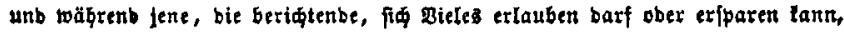
was ber bramatifien geftattet ober veriagt tif, bat biefe, bie borftellenbe, enger

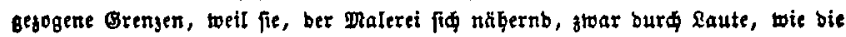
epifhe Diфtung, aber zuglei由 burd Rörper, twie bie bilbenbe Sunft, toirlt, unb niфt twie fene gebroden bie 5arblung in ber Bergangenbett, fonbern felgft bie 5anblung ber Bergangenbeit unmittelbar alß̈ Iebenbig betoegte Begentoart bor भug' unb Dgr bringt. Er Iann babit Hidt bermeiben, auf bie verfdiebenartige

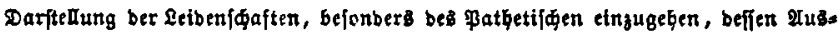
brud er niकt auf bastenige eingeengt wiffen toill, wab bie ftaunenbe Betwunberung ber 3 uf fouer erwedt, toie es bei ben Franjofen ber Braud wax, bem er bielmebr

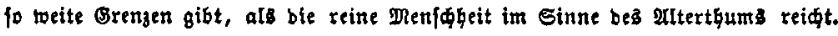
Diefe aber geht, fo toeit bie sunft fig ihrer bebienen barf, nidt Hber bie Grengen

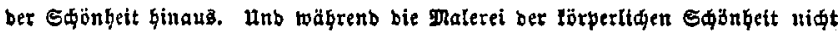
entbebren tann, ift fie für bie poefie, bei ber ftet 3 ber Bebanfe bie Gauptjade bleibt, bon untergeorbnetcm Bertbe, ba fie bem Diøter, ben bas gange uners

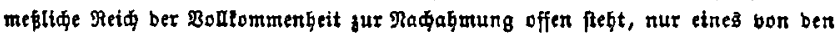

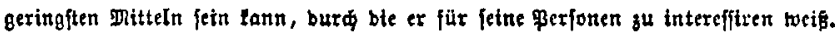

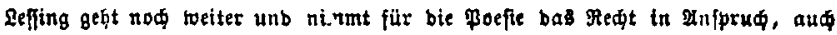

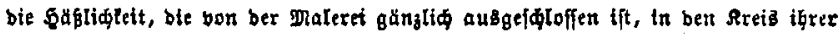

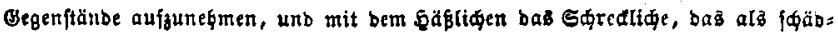

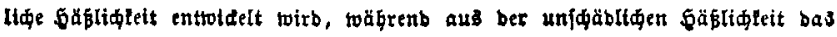

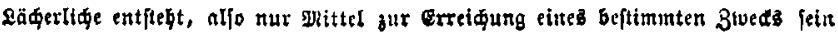




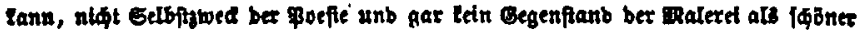

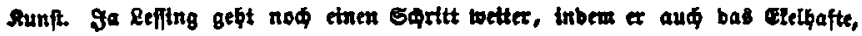

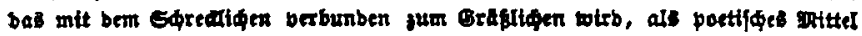

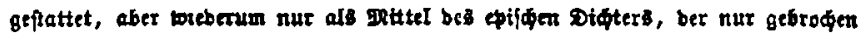

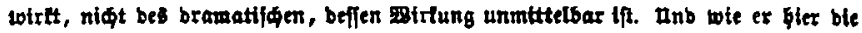

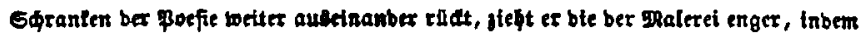

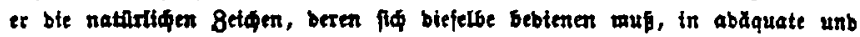

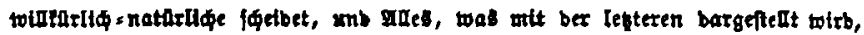
sie ber cinbloungblraft in abdquate ent ju verwanbeln aberlafen bleibt, als

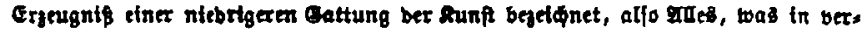
tingten Mafpabe gebalten expeint, befoaber alfo gintaluren unb gefonittene

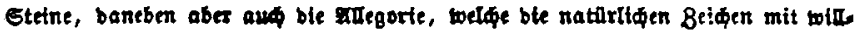

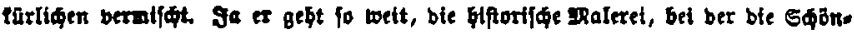

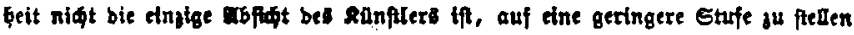

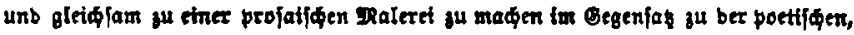

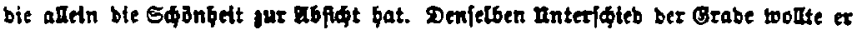

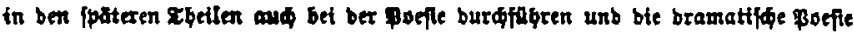
ats bie bogfte auffellen Diefen ghell fetner gefbett beganbelte ex bann in ber

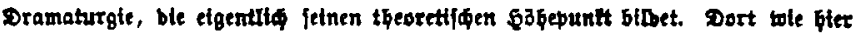

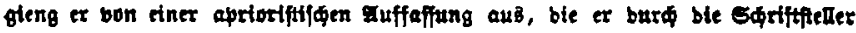

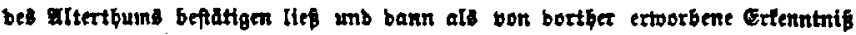

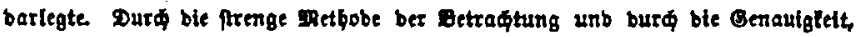

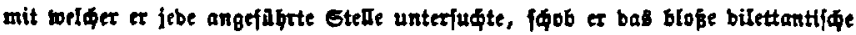

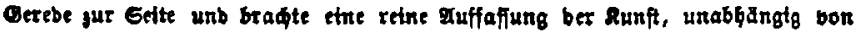
ber Betwenbung tiprex eneugutfie, jux Belturg.

a. coebele. 